\title{
Health Policy Challenges in a Decentralized Federal State: The Situation in Switzerland
}

\author{
Chastonay Philippe*, MD, MPH \\ Lecturer, University of Fribourg, 1700 Fribourg \\ Simos Jean, PhD
}

Senior lecturer, Institute of Global Health, University of Geneva, Geneva

\section{Cantoreggi Nicola}

Researcher and Lecturer, Institute of Global Health, University of Geneva, Geneva Mattig Thomas, JD, MPH

Director and professor, Swiss Health Promotion Foundation, Bern and Institute of Global Health, University of Geneva, Geneva

\begin{abstract}
In Switzerland, health care, disease prevention and health promotion policies are the responsibility of three government tiers: the federal authorities, the cantons, and the communes acting in a decentralized framework.

During the 1990s and the first decade of the $21^{\text {st }}$ century, the federal state elaborated strategic frameworks for disease prevention and health promotion. The lack of systematic data collection was partly alleviated by the creation of an Observatory of health (OBSAN) that produces reports for the cantons on the basis of a cyclic federal survey. A federal law on health promotion and prevention reached a very advanced stage, but closely failed to muster the consensus needed to pass.

The trend towards more governance and coordination at the federal level is not univocal. On one hand, some recent or upcoming decisions, for example in the matter of the regulation of land use or fiscal policy, would tend to reinforce the centralized competencies. On the other hand, we can observe a definite trend of funding cuts at the federal level, along the lines of a more general intention to "untangle" financial and political responsibilities back to the Cantons.
\end{abstract}

The development of equitable and sensible disease prevention and health promotion policies in a decentralized framework carries its unique set of risks and opportunities.

Keywords: Federalism, health reform, health promotion, disease prevention, governance

\section{BACKGROUND}

Switzerland, a federal state since 1848, with a current population of 8 million, is composed of 26 cantons, sovereign in all matters that are not specifically designated the responsibility of the federal government [1]. Health care, disease prevention and health promotion policies are the responsibility of three government tiers: the federal authorities, the cantons and the communes.

On a long-term prospect, the development of the role of the federal state in health affairs has been closely related to federal laws regulating mandatory insurance coverage for accidents (LAMA, 1912, then LAA, 1959), invalidity (LAI, 1959) and disease (LAMal, 1996). The cantons have kept the core responsibility and a high degree of independence in conducting health policies: regulation of health matters, provision of health care (including hospital planning and control), disease prevention, health promotion, health education and the implementation of federal laws. There is no Health Act as a legal framework at the federal level [2].

Regarding specifically disease prevention and health promotion, projects varied widely in scope and nature: "the system evolved in largely fragmented and uncoordinated fashion" [1]. Up until 1989, there were no strategic cantonal objectives covering the whole of Switzerland and no means of 
implementing national projects. Actually, the heterogeneousness of cantonal health related policies has numerous and often long time date back reasons: different population structure and distribution (urban, rural or mixed), institutional and political evolution, size and available resources between cantons, sharing of tasks with the lower level (municipalities), specific weight of political parties (i.e. populists ones), even different cultural and religious background (Catholic or Protestant, 4 national languages and a large number of dialects). Swiss governance could be compared, despite of the scale difference, with the U.S.'s one: situation, needs and expectations are quite different between, for instance, California and Iowa or between New York City and Utah.

Emerging demographic and financial challenges to the health system have fuelled concerns to further develop and coordinate the disease prevention \&health promotion policies, a need that has been highlighted in three international assessments of Switzerland's health system since 2000 [1,2,3,4]. The Swiss Foundation for Health Promotion was set up partly to remediate this situation. It started providing a standardized framework for planning evaluation, tools for quality assessment, and targeted co-financing of programs promoting healthy nutrition and physical activity in the Cantons since 2005[5].

\section{RECENT DEVELOPMENTS}

During the $1990 \mathrm{~s}$ and the first decade of the $21^{\text {st }}$ century, the federal state elaborated strategic frameworks for disease prevention and health promotion. The lack of systematic data collection was partly alleviated by the creation of an Observatory of health (OBSAN) that produces reports for the cantons on the basis of a cyclic federal survey. A federal law project on health promotion and disease prevention reached a very advanced stage [6], but closely failed to muster the consensus needed to pass. A new federal-level legal framework to improve the collection and quality of cancer is in development.

Indeed, the trend towards more governance and coordination at the federal level is not univocal. On one hand, some recent or upcoming decisions, for example in the matter of the regulation of land use or fiscal policy, would tend to reinforce the centralized competencies. On the other hand, we can observe a definite trend of funding cuts at the federal level, along the lines of a more general intention to "untangle" financial and political responsibilities back to the Cantons. At the central level, this has resulted in the reduction or suppression of some health prevention programs. The retreat of direct/linked federal funding has also affected activities and priorities in the communes. This trend might have reactivated long unresolved questions about appropriate governance: "While the highly decentralized implementation may strengthen innovation, the system's conflict-resolution capacity, as well as its flexibility and adaptability, it does not ensure consistent policy outcomes"[7].

Among the OECD countries, Switzerland ranks $7^{\text {th }}$ by the share of total health spending in the GDP; this share has increased from $7.9 \%$ in 1990 to $11 \%$ in 2013 [8]. The overall spending in health prevention and promotion activities (typically around $2 \%$ of health budgets) lagged below the OECD countries average for the last decade. Participation in programs such as breast cancer screening varies widely between cantons [9]. Significant regional differences in cardiovascular factors screening and management have also been reported [10]. However, Cantons have been strengthening their own legal bases to conduct disease prevention and health promotion policies, and some of them have been producing increasingly sophisticated policy- and implementation documents $[11,12,13,14,15,16$, 17].

\section{Some Challenges/InNovations}

A recent study points out that many policymakers and senior administrators tend to adopt a fragmented, case-by-case approach being reluctant to consider social inequalities in health as a general problem [18]. Well-funded external actors can exert significant leverage too: for example, the Tobacco industry is well known to have deployed successful strategies to influence tobacco policy making in Switzerland [19] and elsewhere. There is substantial evidence that actors in the food industry have adopted similar practices [20]. Different influences may be found at cantonal as well at the federal levels. A wide, loose alliance of industry interests played no small role in the rejection of the draft prevention law mentioned earlier.

The limited resources available for disease prevention and health promotion might also severely curtail the scope and number of actions. In this context, we observe a rapid uptake of projects 
accompanied by co-financing. The fact is that a national institution with a public mandate, in this case, the Swiss Health Promotion Foundation, focused on a clear strategy in implementing programmes and policies in healthy nutrition habits and physical activity targeting children and youth in all Swiss cantons, appears to have strongly impacted the selection of priority themes in most of the cantons. This process appears to be exerting a very positive role in promoting harmonization, capacity building and quality control of the various projects selected and executed by the cantons. This result is fully in line with Klibanoff's model of decentralization, where a simple conditional transfer may foster the desired (optimal) outcome, in the absence of coercion and respecting the actor's autonomy [21].

Other innovations that appear to be working towards harmonization are strengthened "horizontal instruments of federalism": inter-cantonal conferences and workgroups such as the Latin Conference of Health and Social Affairs, a body of cantonal Ministers of health. The latter, together with the Swiss Health Promotion Foundation, has recently edited a guidance document [22] aiming to adopt more homogeneous criteria in disease prevention and health promotion plans. This appears as an incremental step in the right direction, even if the guidelines might still be subject to quite broad interpretation.

\section{Decentralized Versus Centralized Policies: What are the Controversies?}

There is a long running debate on the respective merits of decentralized and centralized frameworks, from fiscal policy to the delivery of public goods. Oates theorized an optimum trade-off between decentralization's costs and benefits [23]. In fiscal matters, OECD data shows a positive relationship between increasing decentralization and growth up to a certain level, the relation turns negative thereafter [24]. In health matters, a recent literature review shows that decentralization is associated both with higher health care expenditures and better health outcomes (life expectancy and infant mortality) [25]. On the other hand, in the absence of strong protective mechanisms, increasing inequity and heterogeneity in the provision of services are well known risks of decentralized frameworks [25]. Policy reversals reflect the uncertainties of theory and empiric data: during the last decade, a growing number of countries, especially in the Nordic and central European realms, recentralized important health system functions [26].

Most of those controversies are present in the still highly decentralized Switzerland. Some aspects are matter of specific policy responses; others remain open challenges. Among them, the question of the territorial disparities: the communes outside the metropolitan areas, remain the weak link in the disease prevention and health promotion framework. Economic interdependency and asymmetry in small, resource-limited administrative units may also hinder the formulation of local health in all policies processes. There is an obvious equity risk.

Civil society and grassroots associations traditionally play a large role in the Swiss health system, especially at the implementation level of disease prevention and health promotion programs. Yet some observers contend that the existing governance favours spheres of technocratic decision-making fail to include the persons most affected by the programs, including the users themselves [27]. Moreover technocrat-dominated groups may be subject to entrenching of professional interest groups, precluding action and innovation. Much remains to be done in terms of effective public participation in the governance of health-related activities.

Some authors have also been highlighting that a flow of information (such as generated by a free press and media) might be a key factor in fostering good governance in highly decentralized contexts [28]. Switzerland features a highly concentrated press, albeit generally assessed as free and widespread access to online sources. Regarding the information supply aspects the public actor's tradition of secrecy has been regulated by a recent law on the access to information [29], yet private actors may easily shield themselves from scrutiny. Whistle blowing, "the act of raising concerns about misconduct within an organization", is viewed today as "a key element of any governance system's transparency and accountability framework" [30] and its peculiar importance in risk management has been highlighted in the context of crisis [31]. Whistle-blowers in the federal administration might benefit from a recent revision of a federal law, while a law is being discussed to increase the protection of whistle-blowers in the private sector [32]. As for the Supreme Court, it has remained quite hostile to this practice [32]. For some observers, widespread "severe cultural deficits" might be at the root of this reluctance [31]. In this domain there is still room for improvements, especially in a 
context where private actors are asking for an expanded role in health services: it is worth noting that the recently voted new Constitution Act of Geneva specifically establishes "adequate protection" for whistleblowers (Art. 26 al 3) [33].

\section{CONCLUSION}

The development of equitable and sensible disease prevention and health promotion policies in a decentralized framework carries its unique set of risks and opportunities. Among the risks, in homogeneity and inequity are at the forefront. Simple conditional transfers (co-financing), administered and supervised by an independent instance, have been highly successful in fostering the adoption of a choice of evidence-based and quality-controlled priority programs in the physical activity and obesity domains, while respecting the actor's autonomy. This scheme might be extended to various other domains of disease prevention and health promotion such as mental health.

Small units in a decentralized system might be vulnerable to entrenched interests and lobbies. Among the actions that might present a large potential for further improvement we identify:

- an expanded role in for the users participation, starting at the early levels of planning and decision-making;

- Any measures tending to promote transparency, public scrutiny and a supervisory flow of information on institutional \& corporate stakeholders active in the health domain.

These results might be especially relevant to national and international health systems seeking to implement health reform and governance through decentralized frameworks. The level of cultural change implied by this transformation should not be under-estimated.

\section{REFERENCES}

[1] Minder A., Schoenholzer H., Amiet M. Health care systems in transition: Switzerland. Copenhague: European Observatory on Health Care Systems and WHO Regional Office for Europe (2000).

[2] OECD/World Health Organization. OECD Reviews of Health Systems: Switzerland 2006. OECD/WHO (2006).

[3] OECD/World Health Organization. OECD Reviews of Health Systems: Switzerland 2011. OECD/WHO (2011).

[4] Bennett J. Investment in Population Health in Five OECD Countries. Paris, OECD: Health Working Papers No2 (2003).

[5] Mattig T.Promotion Santé Suisse: Un acteur oeuvrant pour la santé de la population. Infosantésuisse20 (4-5), 8-9 (2015).

[6] Office fédéral de la santé publique OFSP.Projet de loi fédérale sur la prévention et la promotion de la santé. Bern: Confédération Suisse (2012).

[7] LinderW, Vatter A. Institutions and outcomes of Swiss federalism: The role of the cantons in Swiss politics. West European Politics 24(2), 95-122 (2010).

[8] Office Fédéral de la Statistique OFS.Statistiques de la santé 2013. Neuchâtel: OFS (2014).

[9] Ess S, Samvidhan A, Frick H, et al. Geographic variation in breast cancer care in Switzerland. Cancer Epidemiology34 (2), 116-121 (2010).

[10] Marques-Vidal P, Paccaud F. Regional differences in self-reported screening, prevalence and management of cardiovascular risk factors in Switzerland. BMC Public Health12, 246 (2000).

[11] Programme cadre en promotion de la santé et prévention pour le Canton du Valais, Période 20112014. Service de la santé publique (VS) (2011).

[12] Plan cantonal de promotion de la santé et de prévention 2007-2011. Priorités pour le canton de Fribourg. Service de la santé publique (FR) (2006).

[13] Programme pluriannuel de prévention et promotion de la santé. République et canton du Jura, Service de la santé publique (JR) (2003).

[14] Prévention et promotion de la santé. Plan directeur du Conseil d'Etat. République et Canton de Neuchâtel. Service de la santé publique (NE) (2009).

[15] Rapport du Conseil d'Etat sur la politique sanitaire 2008 - 2012. Canton de Vaud (VD) (2007). 
[16] Plan cantonal genevois de promotion de santé et de prévention 2007/2010. Direction générale de la santé(2007).

[17] Hämmig O. Soziale Beziehungen und Gesundheit im Kanton Zürich. Zürich: Institut für Epidemiologie, Biostatistik und Prävention der Universität Zürich (2016).

[18] Lehmann, P.Inégalités sociales et santé en suisse. Analyse des actions concrètes menées par et dans les cantons visant à diminuer les inégalités sociales face à la santé. Lausanne, HECV-Santé (2010).

[19] Lee CY, GlantzSA. The Tobacco Industry Successful Efforts to Control Tobacco Policy Making in Switzerland. San Francisco: Division of Adolescent Medicine and Institute for Health Policy Studies, University of California (2001).

[20] Brownell KD, Warner K. The Perils of Ignoring History: Big Tobacco Played Dirty and Millions Died. How Similar Is Big Food? Milbank Quarterly 87(1), 259-94(2009).

[21] KlibanoffP, Morduch J. Decentralization, Externalities, and Efficiency. The Review of Economic Studies 62(2), 223-247 (1995).

[22] Lehmann P. Plan cantonal de prévention et promotion de la santé: guide d'élaboration. Lausanne: HECV-Santé (2009).

[23] Oates WE. On the Theory and Practice of Fiscal Federalism. In Auerbach AJ, Shaviro DN, eds. Institutional Foundations of Local Public Finance: Economic and Legal Perspectives. Cambridge MA: Harvard University Press 165-188 (2008).

[24] ThiessenU.Fiscal Decentralisation and Economic Growth in High-Income OECD Countries. Fiscal Studies24 (3), 237-274 (2003).

[25] Alves J, Peralta S, Perelman J. Efficiency and equity consequences of decentralization in health: an economic perspective. Revista Portuguesa de Saúde Pública 31(1), 74-83 (2013).

[26] SaltmanRB, Bankauskaite V, Vrangbaek K. Decentralization in Health Care. Strategies outcomes. Maidenhead, England: Open University Press (2007).

[27] WältiS, Küjbler D, Papadopoulos Y. How democratic is "governance"? Lessons from Swiss drug policy. Governance 17(1), 83-113 (2004).

[28] Lessmann, C, Mark wardt,G. One Size Fits All? Decentralization, Corruption and the Monitoring of Bureaucrats. World Development 38(4), 631-646 (2010).

[29] Pasquier M., Villeneuve, JP. Access to information in Switzerland. From secrecy to transparency. Open Government: a Journal on Freedom of Information2 (2), 20-32 (2006).

[30] Groeneweg S. Three Whistleblower Protection Models: A Comparative Analysis of Whistleblower Legislation in Australia, the United States and the United Kingdom. Toronto: Public Service Commission of Canada (2006).

[31] Hofmeister AE. A suitable instrument to improve public corporate governance? Annuaire SSS1, 117-129 (2010).

[32] Junod V. Whistleblowing dans le secteur médical: trouver l'équilibre entre des intérêts divergents. Rev Med Suisse 8(338), 956-958 (2012).

[33] République et canton de Genève. Constitution de la République et canton de Genève. Genève (2012). 